\title{
Evaluation of safety, feasibility and the long-term outcomes of colorectomy for colorectal adenocarcinoma in patients older than 80 years of age
}

\author{
NORIO YUKAWA, TORU AOYAMA, TSUTOMU SATO, TAKASHI OSHIMA, \\ TAKAKI YOSHIKAWA, YASUSHI RINO and MUNETAKA MASUDA \\ Department of Surgery, Yokohama City University, Yokohama, Kanagawa 236-0004, Japan
}

Received March 22, 2017; Accepted July 20, 2017

DOI: $10.3892 /$ mco.2017.1380

\begin{abstract}
The short- and long-term outcomes of colorectomy for colorectal adenocarcinoma have not been fully evaluated in elderly patients. The present retrospective study investigated patients who underwent curative surgery for colorectal cancer at the Department of Surgery, Yokohama City University (Yokohoma, Japan). The patients were categorized into two groups: Elderly patients (70-79 years of age; group A) and extremely elderly patients ( $\geq 80$ years of age; group B). The rates of surgical morbidity, surgical mortality, overall survival (OS), and recurrence-free survival (RFS) in the two groups were compared. A total of 191 patients were evaluated in the current study. Of these, 137 patients were included in group A, and 54 were included in group B. With the exception of the American Society of Anesthesiology physical status score, there were no significant differences in the preoperative clinicopathological outcomes of the two groups. The overall complication rates in groups A and B were 12.4 and $16.7 \%$, respectively, and did not differ to a statistically significant extent $(\mathrm{P}=0.440)$. In addition, surgical mortality was not observed in either group. The 5-year OS and RFS rates were similar between the group A and $\mathrm{B}$ patients (75.6 vs. $76.9 \% ; \mathrm{P}=0.5537$; and 71.9 vs. $62.2 \%$; $\mathrm{P}=0.192$, respectively). The short-term outcomes and long-term survival following colorectomy for colorectal adenocarcinoma among patients in the 70-79 years of age group, and those who were $\geq 80$ in the current study were almost equal. Thus, it is not necessary to avoid colorectomy for colorectal adenocarcinoma in elderly patients simply because of their age.
\end{abstract}

Correspondence to: Dr Norio Yukawa, Department of Surgery, Yokohama City University, 3-9 Fukuura, Kanazawa-Ku, Yokohama, Kanagawa 236-0004, Japan

E-mail: nryukawa@mac.com

Key words: colorectal cancer, elderly patient, colorectomy

\section{Introduction}

Every year, more than 1.36 million individuals are diagnosed with colorectal cancer (CRC) worldwide. CRC is the third most frequent cancer-related cause of death $(1,2)$. Complete resection is essential for obtaining a cure in patients with CRC.

The number of elderly patients is rapidly growing worldwide. With individuals of $\geq 80$ years of age representing the fastest growing subset of the population, the management of complex surgical issues promises to become even more challenging $(3,4)$. However, previous studies have excluded patients in this age group. Furthermore, few authors have evaluated the short- and long-term outcomes of colorectomy for colorectal adenocarcinoma patients of $\geq 80$ years of age $(5,6)$. Thus, the short-term outcomes and long-term survival of elderly patients who undergo colorectomy for colorectal adenocarcinoma remain unclear. In addition, elderly patients often have co-morbidities and age-related physiological problems that can lead to greater postoperative complications or poorer survival in comparison to non-elderly patients (4).

We retrospectively investigated the short-term outcomes and long-term survival after colorectomy for colorectal adenocarcinoma in patients of $\geq 80$ years of age and compared them with patients who were 70-79 years of age.

\section{Patients and methods}

Patients. This was a retrospective single-institutional study. The patient records were retrieved from the collected database of the Department of Surgery, Yokohama City University (Yokohoma, Japan), between March 2000 and April 2015. The inclusion criteria were as follows: i) Histologically proven colorectal cancer, ii) $>20$ years of age, and iii) underwent curative surgery with lymph node dissection for colorectal cancer as the primary treatment. The patients were categorized into two groups: Elderly patients ( $\geq 80$ years of age, Group A) and non-elderly patients (70-79 years of age, Group B).

Surgical procedure and adjuvant chemotherapy. All colorectomies were performed in accordance with standardized procedures that have been described elsewhere (7). Briefly, resection of the colon or rectum with D3 dissection 
Table I. The baseline characteristics of the study patients.

\begin{tabular}{|c|c|c|c|}
\hline \multirow[b]{2}{*}{ Characteristics } & \multicolumn{2}{|c|}{ No. of patients $(\%)$} & \multirow[b]{2}{*}{ P-value } \\
\hline & $\begin{array}{c}\text { Group A } \\
\text { (70-79 years) } \\
(\mathrm{n}=137)\end{array}$ & $\begin{array}{c}\text { Group B } \\
(\geq 80 \text { years }) \\
(n=54)\end{array}$ & \\
\hline Age (years) & & & - \\
\hline $\begin{array}{l}\text { Median } \\
\text { (Range) }\end{array}$ & $\begin{array}{c}74 \\
(70-79)\end{array}$ & $\begin{array}{c}83 \\
(80-94)\end{array}$ & \\
\hline Sex & & & 0.552 \\
\hline Male & $88(64.2)$ & $32(59.3)$ & \\
\hline Female & $49(35.8)$ & $22(40.7)$ & \\
\hline ASA-PS & & & 0.048 \\
\hline 1 & $62(45.3)$ & $16(29.6)$ & \\
\hline $2-3$ & $75(54.7)$ & $38(70.4)$ & \\
\hline Tumor location & & & 0.539 \\
\hline Right-side colon & $49(35.8)$ & $24(44.4)$ & \\
\hline $\begin{array}{l}\text { Left-side } \\
\text { colon-rectum }\end{array}$ & $88(64.2)$ & $30(55.6)$ & \\
\hline Clinical $\mathrm{T}$ factor & & & 0.631 \\
\hline $\mathrm{T} 1$ & $22(16.1)$ & $10(18.5)$ & \\
\hline $\mathrm{T} 2$ & $22(16.1)$ & $12(22.2)$ & \\
\hline $\mathrm{T} 3$ & $49(35.6)$ & $21(38.9)$ & \\
\hline $\mathrm{T} 4$ & $44(32.2)$ & $11(20.4)$ & \\
\hline Clinical $\mathrm{N}$ factor & & & 0.630 \\
\hline Negative & $83(60.6)$ & $33(38.9)$ & \\
\hline Positive & $54(39.4)$ & $21(61.1)$ & \\
\hline
\end{tabular}

ASA-PS, American Society of Anesthesiology physical status.

was performed according to the Japanese Classification of Colorectal Carcinoma (sixth edition) (8). The approaches for colonic mobilization were decided by the surgeon. For right-sided lesions, the vascular pedicles were divided at their origin, and the draining lymph nodes (nos. 203, 213 and 223) were resected along the superior mesenteric vein. For left-sided lesions, the lymph nodes at the root of the inferior mesenteric artery (no. 253) were removed with high ligation, or with the preservation of the left colic artery and ligation of the root of the superior rectal artery. When a histological examination of the resected specimen revealed a pathological stage of III, 5-FU based adjuvant chemotherapy was administered (9).

Definition of postoperative complications. The grade 2-5 postoperative complications (according to the Clavien-Dindo classification) that occurred during hospitalization and/or within 30 days after surgery were retrospectively determined from the patient records (10). Grade 1 complications were not evaluated, to exclude the possibility of a description bias in the patient's records.

Follow-up. The patients were followed up at outpatient clinics. Hematological tests and physical examinations were performed at least every three months for five years. In the
Table II. The surgical and pathological findings.

\begin{tabular}{|c|c|c|c|}
\hline \multirow[b]{2}{*}{ Characteristics } & \multicolumn{2}{|c|}{ No. of patients (\%) } & \multirow[b]{2}{*}{ P-value } \\
\hline & $\begin{array}{c}\text { Group A } \\
\text { (70-79 years) } \\
(n=137)\end{array}$ & $\begin{array}{c}\text { Group B } \\
(\geq 80 \text { years }) \\
(n=54)\end{array}$ & \\
\hline Type of surgery & & & 0.651 \\
\hline Open & $97(70.8)$ & $40(74.1)$ & \\
\hline Laparoscopic & $40(29.2)$ & $14(25.9)$ & \\
\hline Operation time (min) & & & 0.030 \\
\hline Median (range) & $230(83-555)$ & $199(90-505)$ & \\
\hline Blood loss (ml) & & & 0.030 \\
\hline Median (range) & $314(5-2,500)$ & $213(30-895)$ & \\
\hline Pathological stage & & & 0.472 \\
\hline 0 & $7(5.1)$ & $2(3.7)$ & \\
\hline I & $30(21.9)$ & $17(31.5)$ & \\
\hline II & $40(29.2)$ & $12(22.2)$ & \\
\hline III & $34(24.8)$ & $17(31.5)$ & \\
\hline IV & $26(19.0)$ & $6(11.1)$ & \\
\hline $\begin{array}{l}\text { No. of harvested } \\
\text { lymph nodes }\end{array}$ & & & 0.733 \\
\hline Median (range) & $17(3-81)$ & $15(4-46)$ & \\
\hline $\begin{array}{l}\text { Postoperative } \\
\text { complications }\end{array}$ & & & 0.440 \\
\hline Yes & $45(32.8)$ & $9(16.7)$ & \\
\hline No & $120(67.2)$ & $45(83.3)$ & \\
\hline $\begin{array}{l}\text { Postoperative } \\
\text { hospital stay (days) }\end{array}$ & & & 0.198 \\
\hline Median (range) & $21(4-115)$ & $20(7-103)$ & \\
\hline
\end{tabular}

patients who received adjuvant chemotherapy, hematological tests and physical examinations were performed at least every two weeks during adjuvant chemotherapy, and at least every three months for five years after the patients finished adjuvant chemotherapy. The CEA and CA19-9 tumor marker levels were checked at least every three months for five years. The patients underwent a CT examination every three months during the first three years after surgery, and then every six months until five years after surgery.

Evaluations and statistical analyses. Overall survival (OS) was defined as the period between surgery and death. Recurrence-free survival (RFS) was defined as the period between surgery and recurrence or death, depending on which preceded. The data of the patients who did not experience an event were censored on the date of the final observation. OS and RFS curves were calculated using the Kaplan-Meier method, and were compared by the log-rank test. Comparisons between the two groups were performed using the unpaired $\chi^{2}$ method or Student's t-test. $\mathrm{P}<0.05$ was considered to indicate statistical significance. The data are expressed as the median (range). The SPSS software package (v11.0 J Win; SPSS, Chicago, IL, USA) was used for all of the statistical analyses. 
Table III. The univariate and multivariate Cox proportional hazards analyses of the clinicopathological factors associated with overall survival.

\begin{tabular}{|c|c|c|c|c|c|c|c|}
\hline \multirow[b]{2}{*}{ Factor } & \multirow[b]{2}{*}{ Number } & \multicolumn{3}{|c|}{ Univariate } & \multicolumn{3}{|c|}{ Multivariate } \\
\hline & & HR & $95 \% \mathrm{CI}$ & P-value & HR & $95 \% \mathrm{CI}$ & P-value \\
\hline Age (years) & & & & 0.212 & & & \\
\hline 70-79 years & 137 & 1.000 & & & & & \\
\hline$\geq 80$ years & 54 & 1.289 & $0.865-1.920$ & & & & \\
\hline Sex & & & & 0.102 & & & 0.083 \\
\hline Female & 71 & 1.000 & & & 1.000 & & \\
\hline Male & 120 & 1.345 & $0.943-1.917$ & & 1.373 & $0.960-1.964$ & \\
\hline Pathological $\mathrm{T}$ factor & & & & 0.694 & & & \\
\hline$-\mathrm{T} 3$ & 136 & 1.000 & & & & & \\
\hline T4- & 55 & 1.097 & $0.692-1.740$ & & & & \\
\hline Pathological $\mathrm{N}$ factor & & & & 0.885 & & & \\
\hline Negative & 75 & 1.000 & & & & & \\
\hline Positive & 116 & 1.029 & $0.702-1.506$ & & & & \\
\hline Tumor location & & & & 0.734 & & & \\
\hline Right-side & 73 & 1.000 & & & & & \\
\hline Left-side rectum & 118 & 1.066 & $0.738-1.539$ & & & & \\
\hline ASA-PS & & & & $<0.001$ & & & $<0.001$ \\
\hline 1 & 78 & 1.000 & & & 1.000 & & \\
\hline $2-3$ & 113 & 3.984 & $2.591-5.851$ & & 3.945 & $2.617-5.945$ & \\
\hline Postoperative surgical complication & & & & 0.991 & & & \\
\hline No & 137 & 1.000 & & & & & \\
\hline Yes & 54 & 1.003 & $0.626-1.606$ & & & & \\
\hline
\end{tabular}

This study was approved by the IRB of the Kanagawa Cancer Center.

\section{Results}

Patient background. A total of 191 patients were eligible for the present study (male, $\mathrm{n}=120$; female, $\mathrm{n}=71$; median age, 77 years; range, 70-94). The median follow-up period was 35.6 months (range, 1-172 months). A total of 137 patients were classified as elderly patients (Group A), and 54 were classified as extremely elderly patients (Group B). The background characteristics of the patients are summarized in Table I. The American Society of Anesthesiology physical status (ASA-PS) score was significantly worse and the incidence of co-morbidities was significantly higher in Group B than in Group A ( $\mathrm{P}=0.048$ and $\mathrm{P}=0.031$, respectively). On the other hand, the tumor location and clinical stage were similar.

Surgical and pathological findings. The operative details and pathological findings are shown in Table II. With regard to the intraoperative outcomes, significant differences were observed between groups $\mathrm{A}$ and $\mathrm{B}$ in the median duration of surgery ( $230 \mathrm{~min}$ vs. $199 \mathrm{~min}, \mathrm{P}=0.030$ ) and the median blood loss ( $314 \mathrm{ml}$ vs. $213 \mathrm{ml}, \mathrm{P}=0.030)$. On the other hand, the type of surgery, the performance of lymph node dissection, and the number of harvested lymph nodes were similar ( $\mathrm{P}=0.651, \mathrm{P}=0.182$, and $\mathrm{P}=0.733$, respectively). No significant differences were observed in the pathological findings of the two groups.

Postoperative complications. The overall complication rates in Groups A and B were 12.4 and $16.7 \%$, respectively and did not differ to a statistically significant extent $(\mathrm{P}=0.440)$. Surgical mortality was not observed in either group. Moreover, the postoperative length of hospital stay was similar (21 days vs. 20 days, $\mathrm{P}=0.198$ ).

Survival analysis. The OS rates at 3 and 5 years after surgery were 28.2 and $75.6 \%$ in Group A and 20.2 and $76.9 \%$ in Group B, respectively (not significant; $\mathrm{P}=0.554$ ). The RFS rates at 3 and 5 years after surgery were 21.4 and $71.9 \%$ in Group A and 16.0 and $62.2 \%$ in Group B, respectively (not significant; $\mathrm{P}=0.829)$. Age was not found to be significantly associated with either the OS or DFS in the univariate or multivariate analyses. The univariate and multivariate analyses of the factors associated with overall survival demonstrated that the ASA-PS score was a significant risk factor. On the other hand, age was not identified as a significant prognosticator in either the univariate or multivariate analyses (Table III). Moreover, the univariate and multivariate analyses demonstrated that the ASA-PS score was a significant risk factor for recurrence-free survival. However, age was not identified as a significant prognosticator for recurrence-free survival in either the univariate or multivariate analyses (Table IV). 
Table IV. The univariate and multivariate Cox proportional hazards analyses of the clinicopathological factors associated with recurrence-free survival.

\begin{tabular}{|c|c|c|c|c|c|c|c|}
\hline \multirow[b]{2}{*}{ Factor } & \multirow[b]{2}{*}{ Number } & \multicolumn{3}{|c|}{ Univariate } & \multicolumn{3}{|c|}{ Multivariate } \\
\hline & & HR & $95 \% \mathrm{CI}$ & P-value & $\mathrm{HR}$ & $95 \% \mathrm{CI}$ & P-value \\
\hline Age (years) & & & & 0.256 & & & \\
\hline 70-79 years & 137 & 1.000 & & & & & \\
\hline$\geq 80$ years & 54 & 1.306 & $0.991-1.994$ & & & & \\
\hline Sex & & & & 0.701 & & & \\
\hline Female & 71 & 1.000 & & & & & \\
\hline Male & 120 & 1.067 & $0.768-1.482$ & & & & \\
\hline Pathological $\mathrm{T}$ factor & & & & 0.086 & & & 0.063 \\
\hline$-\mathrm{T} 3$ & 136 & 1.000 & & & 1.000 & & \\
\hline T4- & 55 & 1.403 & $0.953-2.066$ & & 1.445 & $0.981-2.128$ & \\
\hline Pathological N factor & & & & 0.248 & & & \\
\hline Negative & 75 & 1.000 & & & & & \\
\hline Positive & 116 & 1.215 & $0.873-1.691$ & & & & \\
\hline Tumor location & & & & 0.279 & & & \\
\hline Right-side & 73 & 1.000 & & & & & \\
\hline Left-side rectum & 118 & 1.197 & $0.864-1.659$ & & & & \\
\hline ASA-PS & & & & $<0.001$ & & & $<0.001$ \\
\hline 1 & 78 & 1.000 & & & 1.000 & & \\
\hline $2-3$ & 113 & 2.620 & $1.843-3.726$ & & 2.851 & $1.814-3.671$ & \\
\hline Postoperative surgical complication & & & & 0.727 & & & \\
\hline No & 137 & 1.000 & & & & & \\
\hline Yes & 54 & 1.076 & $0.713-1.625$ & & & & \\
\hline
\end{tabular}

\section{Discussion}

The short- and long-term outcomes of colorectomy for colorectal adenocarcinoma in patients of $\geq 80$ years of age were similar to those of patients who were 70-79 years of age. Thus, our results suggest that colorectomy is a safe option for colorectal adenocarcinoma that can achieve similar survival benefits, regardless of the age of the patient. Furthermore, the results suggest that it may be performed in extremely elderly patients who are deemed optimal candidates in all other respects.

The extremely elderly and elderly patients showed similar short-term outcomes, including the overall postoperative complication rates, mortality rates, and length of hospital stay. Similar results were observed in previous reports. For example, Bircan et al evaluated the impact of colorectal surgery on the short-term results and analyzed the factors that had the potential to influence these results in elderly patients, in a study conducted between January 2008 and December 2013. A total of 265 patients were enrolled and analyzed in that retrospective study (6). Among the patients who underwent surgery during the study period, 110 were between 60 and 69 years of age (group 1), 99 were between 70 and 79 years of age and 56 were $\geq 80$ years of age. A comparison of the postoperative surgical complications, revealed no significant differences in the postoperative surgical complications of the three groups (10.0, 13.1 , and $21.4 \%$, respectively). In addition, Pelloni reviewed the records of 300 consecutive colorectal resections that were performed between 2002 and 2008 (11). Their patients were divided into two groups: Group A comprised patients who were $<80$ years of age, while group B included patients who were $\geq 80$ years of age. They found that the complications, mortality and hospital stay of the two groups were comparable. By contrast, Kang et al evaluated the impact of age on the postoperative clinical outcomes after the laparoscopic resection of colorectal cancers in 578 patients (12). The patients were divided into 6 groups according to their age using 70, 75, and 80 years as cut-off values: $<70, \geq 70$ years; $<75, \geq 75$ years; and $<80, \geq 80$ years. They reported that the overall postoperative complication rate was $21.1 \%(n=122)$. There were 4 cases of operative mortality $(0.7 \%)$. The postoperative complication rates in the elder group were consistently higher at all three cut-off ages; however, only the cut-off of 80 years showed a statistically significant difference between the younger and elder groups. In addition, a trend towards a higher grade of complications (according to the Clavien-Dindo classification) was noted, but significant differences between the older and younger groups were only observed when a cut-off of 80 years was used. These data suggest that when complications occur in elderly patients, they rapidly increase in severity.

In the present study, the 5-year OS rates and RFS rates of the elderly and non-elderly patients were similar $(75.6 \%$ vs. $76.9 \%, \mathrm{P}=0.554$ and $71.9 \%$ vs. $62.2 \%, \mathrm{P}=0.829$, respectively). The median OS and RFS were similar between the two 
groups. In addition, the univariate and multivariate analyses revealed that age was not significantly associated with either OS or DFS. Similar results have been observed in previous studies. Araujo et al evaluated the risk factors for mortality, morbidity, and long-term survival in elderly patients with colorectal cancer in comparison to younger patients (13). In that study, patients who underwent surgery for colorectal cancer were divided into 2 groups according to their age; Group 1 ( $\geq 75$ years, $n=90)$ and group $2(<75$ years, $n=430)$. The comparison of the two groups revealed that a poor clinical status (as defined by the ASA-PS score) $(\mathrm{P}=0.008)$ and the performance of blood transfusion $(\mathrm{P}=0.003)$ were more frequently observed in group 1 than in group 2 . On the other hand, there was no significant difference between the 2 groups with regard to cancer-related survival at 1,2 , and 4 years. Moreover, Mäkelä et al evaluated the surgical outcomes in elderly patients who underwent colorectomy for CRC. They analyzed the data of 231 patients of $\geq 75$ years of age who underwent surgery for CRC between 1980 and 1993 (14). They found that the overall 5-year and 10-year and survival rates were 28 and $4 \%$, respectively, while the median survival was 33 months (range 0-150 months). In addition, age alone was not a risk factor for long-term survival. They concluded that acceptable long-term survival can be achieved in patients of $\geq 75$ years of age if patients with extensive distant metastases and those whose general condition is too poor to withstand a major operation are treated conservatively.

Special attention is required when interpreting our results because the present study was a case series and was performed in a single center. The morbidity rate might have been affected by the surgical indications, and this selection bias represents a major limitation. In these cases, the surgical indication was determined by four physicians, including an anesthesiologist, who took into consideration the activities of daily living, performance status, medical history, physical examinations, and organ function-as is done in general community hospitals. However, there is a possibility that only patients with a good status were selected because our hospital is a university hospital. Elderly patients who have co-morbidities and visit general hospitals often undergo surgery at the hospital in which they receive their diagnosis. Indeed, the ASA-PS score, the incidence of co-morbidities, and the pre-operative laboratory data were similar between the two groups. Furthermore, surgical skill was an important factor with respect to surgical morbidity and mortality. On reviewing our data of non-elderly patients, the overall mortality and morbidity rates in the non-elderly patients were 0 and $12.4 \%$, respectively, which were similar to (or even lower than) the data of previous reports, suggesting that our surgical skill is average. Considering these limitations of the present study, further studies should be performed to focus on the patients who should be selected as candidates and who can be expected to do well after colorectomy for colorectal cancer.

In summary, both the short-term outcomes and long-term survival after colorectomy for colorectal cancer were almost equal in the elderly and non-elderly patients of this study. Thus, it is not necessary to avoid colorectomy for colorectal cancer simply because of age in elderly patients who may otherwise be good candidates for surgery.

\section{References}

1. Ferlay J, Soerjomataram I, Dikshit R, Eser S, Mathers C, Rebelo M, Parkin DM, Forman D and Bray F: Cancer incidence and mortality worldwide: Sources, methods amd major patterns in GLOBOCAN 2012. Int J Cancer 136: E359-E386, 2015.

2. Bonjer HJ, Deijen CL, Abis GA, Cuesta MA, van der Pas MH, de Lange-de Klerk ES, Lacy AM, Bemelman WA, Andersson J, Angenete E, et al: A randomized trial of laparoscopic versus open surgery for rectal cancer. N Engl J Med 372: 1324-1332, 2015.

3. Watters JM: Surgery in the elderly. Can J Surg 45: 104-108, 2002.

4. Surgery for colorectal cancer in elderly patients: A systematic review. Colorectal cancer collaborative group. Lancet 356: 968-974, 2000

5. Bottino V, Esposito MG, Mottola A, Marte G, Di Maio V, Sciascia V, Nunziante M, Fregola G, Cuzzovaglia S, Galante F, et al: Early outcomes of colon laparoscopic resection in the elderly patients compared with the younger. BMC Surg (Suppl): 8,2012.

6. Bircan HY, Koc B, Ozcelik U, Adas G, Karahan S and Demirag A: Are there any differences between age groups regarding colorectal surgery in elderly patients? BMC Surg 14: 44, 2014.

7. Yamamoto S, Inomata M, Katayama H, Mizusawa J, Etoh T, Konishi F, Sugihara K, Watanabe M, Moriya Y and Kitano S; Japan Clinical Oncology Group Colorectal Cancer Study Group: Short-term surgical outcomes from a randomized controlled trial to evaluate laparoscopic and open D3 dissection for stage II/III colon cancer: Japan Clinical Oncology Group Study JCOG 0404. Ann Surg 260: 23-30, 2014.

8. Japanese Society for Cancer of the Colon and Rectum: General Rules for Clinical and Pathological Studies on Cancer of the Colon, Rectum and Anus. 8th edition. Kanehara-Shuppan, Tokyo, Japan, 2013 (In Japanese).

9. Japanese Society for Cancer of the Colon and Rectum: JSCCR Guidelines 2010 for the Treatment of Colorectal Cancer. Kanehara-Shuppan, Tokyo, Japan, 2010.

10. Dindo D, Demartines N and Clavien PA: Classification of surgical complications: A new proposal with evaluation in a cohort of 6336 patients and results of survey. Ann Surg 240: 205-213, 2004.

11. Pelloni A: Colorectal surgery in patients over 80 years old. Hepatogastroenterology 59: 120-123, 2012.

12. Kang T, Kim HO, Kim H, Chun HK, Han WK and Jung KU: Age over 80 is a possible risk factor for postoperative morbidity after a laparoscopic resection of colorectal cancer. Ann Coloproctol 31: 228-234, 2015

13. Araujo SE, de Paris Caravatto PP, de Campos FG, da Silva e Sousa AH Jr, Nahas SC, Kiss DR and Cecconello I: Colorectal cancer among patients aged 75 years or over. Hepatogastroenterology 54: 427-430, 2007.

14. Mäkelä JT, Kiviniemi H and Laitinen S: Survival after operations for colorectal cancer in patients aged 75 years or over. Eur J Surg 166: 473-479, 2000. 